CASE REPORT

\title{
Enzyme replacement therapy in the management of longstanding skeletal and soft tissue salmonella infection in a patient with Gaucher's disease
}

\author{
M Margalit, N Ash, A Zimran, H Halkin
}

Postgrad Med J 2002;78:564-565

A splenectomised patient with Gaucher's disease who developed multiple foci of osteomyelitis and soft tissue abcesses, after a severe episode of group $C$ salmonella sepsis, is described. Aggressive antibiotic treatment and surgical drainage had little effect and the patient's condition continued to deteriorate. With initiation of enzyme replacement therapy (ERT) in addition to specific antibiotic treatment, defervescence and gradual healing occurred. Complete resolution of the infection was seen after 15 months. The possible role of ERT in healing bacterial infections in Gaucher's disease is discussed.

$\mathrm{P}$ atients with Gaucher's disease, particularly those who have undergone splenectomy, are susceptible to bacterial infections. ${ }^{1}$ Although rare, infections with salmonella may be life threatening and resistant to standard treatment, as illustrated by the following case.

\section{CASE REPORT}

A 41 year old man, an aeronautical engineer of Ashkenazi Jewish origin, was hospitalised in November 1991 with fever (temperature $>39.5^{\circ} \mathrm{C}$ ), rigors, prostration, severe jaundice, and respiratory failure. Septic shock was evident with disseminated intravascular coagulation and adult respiratory distress syndrome.

The medical history was remarkable for Gaucher's disease, which was diagnosed by bone marrow biopsy at age 6 years, and for a partial factor XI deficiency. Seven years before presentation, the patient had undergone an elective splenectomy because of massive splenomegaly and pancytopenia. Five years before presentation the patient required right total hip replacement after suffering a pathological subcapital fracture of the right femur. Within three months a left total hip replacement was also required due to avascular necrosis of the left femoral head.

Physical examination revealed an ill appearing, severely tachypnoeic, and dyspnoeic patient with moderate hepatomegaly.

Abnormal laboratory findings included a low haemoglobin concentration of $73 \mathrm{~g} / \mathrm{l}(7.3 \mathrm{~g} / \mathrm{dl})$, white blood cell count of 4.6 $\times 10^{9} / \mathrm{l}$, and platelet counts $16 \times 10^{9} / \mathrm{l}$. He also had markedly abnormal blood chemistry values (total bilirubin $114 \mu \mathrm{mol} / \mathrm{l}$, aspartate aminotransferase $8.55 \mu \mathrm{kat} / \mathrm{l}$, alanine aminotransferase $5.35 \mu \mathrm{kat} / \mathrm{l}$, alkaline phosphatase $14.05 \mu \mathrm{kat} / \mathrm{l}$, lactate dehydrogenase $7.78 \mu \mathrm{kat} / \mathrm{l}$, albumin $19 \mathrm{~g} / \mathrm{l}$, and calcium 1.69 $\mathrm{mmol} / \mathrm{l}$ ). Urinalysis was positive for bilirubin; blood cultures were positive for group C salmonella.

The patient's condition stabilised with supportive treatment and appropriate parenteral antibiotics (initially ampicillin, second ofloxacin, then ceftriaxone and finally, a combination of chloramphenicol and trimethoprim-sulfamethoxazole as per culture sensitivity). There was resolution of respiratory dysfunction and jaundice, gradual normalisation of laboratory findings, and blood cultures were negative. The patient, however, remained febrile $\left(>38^{\circ} \mathrm{C}\right)$. Twelve days after admission, multiple soft tissue abcesses appeared, followed by multifocal osteomyelitis. Cultures obtained from bone and soft tissue lesions yielded group C salmonella.

Over the following weeks, despite aggressive antibiotic treatment and a number of surgical interventions, new soft tissue and skeletal infectious foci, as well as multiple pus-draining fistulae, appeared. Interestingly, there was no evidence of prostheses related infection.

It was at this point, two months after his admission to hospital, that enzyme replacement therapy (ERT) with alglucerase $(60 \mathrm{U} / \mathrm{kg} / \mathrm{month}$ biweekly) was initiated. Within four weeks, a dramatic improvement was noted, allowing the patient to be discharged from hospital with continuation of ERT and intravenous antibiotic treatment (ofloxacin and trimethoprim-sulfamethoxazole) on an outpatient basis. There was resolution of all foci of infection and closure of fistulae. Within three months after discharge from hospital, the patient returned to work on a full time basis; by 18 months he was able to return to his previous lifestyle without limitations. During 10 years of follow up, there have been no further hospitalisations; the patient continues to receive ERT on a bimonthly basis.

\section{DISCUSSION}

Patients with Gaucher's disease, a sphingolipidosis characterised by abnormal accumulation of glucocerebroside in cells of the monocyte-macrophage system, may be susceptible to bacterial infections, particularly if they have undergone splenectomy. ${ }^{1}$ The tendency to infections may not be universal, ${ }^{2}$ but in some patients it is an important complication of Gaucher's disease, entailing significant morbidity. ${ }^{3}$

Over the past 15 years the annual incidence of infections with the non-typhoidal salmonella species has been on the rise in Israel as elsewhere in the industrialised world. ${ }^{4}$ Extraintestinal manifestations of non-typhoidal salmonella infections, which may not be preceded by an episode of gastroenteritis, include bacteraemia and focal infections such as osteomyelitis, although soft tissue abcesses are rare. ${ }^{5}$ Conditions predisposing to non-typhoidal salmonella bacteraemia and extraintestinal manifestations are characterised by defects in cellular immunity, such as underlying (particularly lymphoid) malignancies, organ transplantation, steroid and cytotoxic therapy, diabetes mellitus, and connective tissue disorders; as well as sickle cell disease (due to deficient complement mediated opsonising activity for salmonella), ${ }^{45}$ and splenectomy. ${ }^{6}$ An increased tendency to salmonella osteomyelitis has also been described in pre-existing bone disease. ${ }^{7}$ Bone infarcts may be seen in Gaucher's disease, and secondary 
infections, particularly after surgical procedures, have been documented, ${ }^{8}$ yet extraintestinal salmonellosis, including salmonella osteomyelitis, is extremely rare in Gaucher's disease. In a review of the literature there was only one such case previously reported, in $1966^{8}$; this report, therefore, is the second.

While some cases of bacterial infections may be attributed to neutropenia due to marked hypersplenism or splenectomy, ${ }^{1}$ this patient was not neutropenic. Additional host factors, including defective function of phagocytic cells $^{239}$ and abnormalities of cellular immunity, ${ }^{10}$ may contribute to decreased systemic resistance to bacterial infections observed in patients with Gaucher's disease. Significantly decreased neutrophil chemotaxis has been shown in one third of patients studied, ${ }^{3}$ and impaired superoxide production by monocytes has also been noted..$^{2}$ Importantly, these defects were reversible with ERT administration. ${ }^{911}$

ERT improves the signs and symptoms of Gaucher's disease $^{1}$; however, its use in acute infections has never been reported. The above studies of phagocyte dysfunction in Gaucher's disease had not yet been published at the time of this patient's hospitalisation, nor were phagocyte function studies performed before the initiation of antibiotics and ERT. Thus, the decision to give ERT as measure of last resort was more intuitive than evidence based. Improvement in haemoglobin concentration and platelet counts, as well as the reduction in hepatomegaly with ERT, ${ }^{1}$ may be anticipated after a minimum of 3-6 months of treatment and hence were neither the expectation nor the motivation for use of ERT in the acute crisis. On the other hand, it was hoped that ERT would induce a cascade of secondary messengers that would effect the immune response. The dramatic improvement, therefore, may be seen in line with this thinking and corroborated by the above studies of improved neutrophil chemotaxis in patients with Gaucher's disease who suffered from chronic infections. ${ }^{11}$ Correction of impaired chemotaxis was seen within weeks of the advent of ERT, whereas the resolution of the tendency to infections was more prolonged. Similarly, in the current case one may speculate that the initial improvement was mediated by enhancement of systemic resistance to infection, possibly by an effect on the white blood cell population, with full recovery several months later.

\section{ACKNOWLEDGEMENT}

The authors thank Dr Deborah Elstein for her editorial assistance in the preparation of this manuscript.

\section{Authors' affiliations}

M Margalit, A Zimran, Gaucher Clinic, Shaare Zedek Medical, Jerusalem, Israel

N Ash, Department of Internal Medicine A, Chaim Sheba Medical Center, Tel Hashomer, Israel

H Halkin, Division of Clinical Pharmacology and Toxicology

Correspondence to: Dr Ari Zimran, Gaucher Clinic, Shaare Zedek Medical Center, POB 3235, Jerusalem 91031, Israel:

zimran@md2.huji.ac.il

Submitted 6 December 2001

Accepted 29 May 2002

\section{REFERENCES}

1 Cox TM, Schofield JP. Gaucher's disease: clinical features and natural history. Bailliere's Clin Haematol 1997; 10:657-89.

2 Liel Y, Rudich A, Nagauker-Shriker O, et al. Monocyte dysfunction in patients with Gaucher disease: evidence for interference of glucocerebroside with superoxide generation. Blood 1994;83:2646-53.

3 Aker M, Zimran A, Abrahamov A, et al. Abnormal neutrophil chemotaxis in Gaucher disease. Br J Haematol 1993;83:187-91.

4 Shimoni Z, Pitlik S, Leibovici L, et al. Nontyphoid salmonella bacteremia: age related differences in clinical presentation, bacteriology and outcome. Clin Infect Dis 1999:28:822-7.

5 Shamiss A, Thaler M, Nussinovitch N, et al. Multiple Salmonella enteritidis leg abcesses in a patient with systemic lupus erythematosus. Postrgrad Med J 1990;66:486-8.

6 Madoff LC, Kasper DL. Introduction to infectious diseases: host-parasite interactions. In: Braunwald E, Fauci AS, Kasper DL, et al, eds. Harrison's principles of internal medicine. 15th Ed. New York: McGraw Hill, 2001 763-7.

7 Santos EM, Sapico FL. Vertebral osteomyelitis due to salmonellae: report of two cases and review. Clin Infect Dis 1999;27:287-95.

8 Finkelstein R, Nachum Z, Reissman P, et al. Anaerobic osteomyelitis in patients with Gaucher's disease. Clin Infect Dis 1992;15:771-3.

9 Marodi L, Kaposzta R, Toth J, et al. Impaired microbicidal capacity of mononuclear phagocytes from patients with type I Gaucher disease: partial correction by enzyme replacement therapy. Blood 1995:86:4645-9.

10 Burstein Y, Zakuth V, Rechavi G, et al. Abnormalities of cellular immunity and natural killer cells in Gaucher's disease. J Clin Lab Immunol 1987;23:149-51.

11 Zimran A, Abrahamov A, Aker M, et al. Correction of neutrophil chemotaxis defect in patients with Gaucher disease by low-dose enzyme replacement therapy. Am J Hematol 1993;43:69-71. 